\title{
Article
}

\section{Endodontic Management of Traumatised Permanent Anterior Teeth}

Phillips, Jillian M., McCann, Catherine T. and Welbury, Richard Available at http://clok.uclan.ac.uk/36813/

Phillips, Jillian M., McCann, Catherine T. and Welbury, Richard ORCID: 00000002-9322-2440 (2020) Endodontic Management of Traumatised Permanent Anterior Teeth. Primary Dental Journal, 9 (4). pp. 37-44. ISSN 2050-1684

It is advisable to refer to the publisher's version if you intend to cite from the work. http://dx.doi.org/10.1177/2050168420963304

For more information about UCLan's research in this area go to http://www.uclan.ac.uk/researchgroups/ and search for < name of research Group>.

For information about Research generally at UCLan please go to http://www.uclan.ac.uk/research/

All outputs in CLoK are protected by Intellectual Property Rights law, including Copyright law. Copyright, IPR and Moral Rights for the works on this site are retained by the individual authors and/or other copyright owners. Terms and conditions for use of this material are defined in the policies page.

\section{CLoK}

Central Lancashire online Knowledge www.clok.uclan.ac.uk

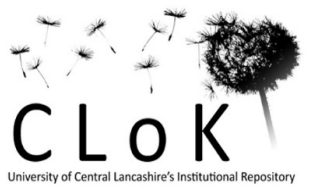


Title: Endodontic management of traumatised permanent anterior teeth

\begin{abstract}
:
Traumatised permanent anterior teeth can require endodontic treatment which may be immediate as part of acute trauma management, or delayed due to the development of sequelae. This paper will enable clinical decision making by exploring a range of situations in which endodontic treatment may be indicated, and also offering practical advice regarding effective endodontic treatment for paediatric dental trauma patients.

Endodontic treatment of traumatised permanent teeth in paediatric patients is often challenging. However, with timely decision making and appropriate treatment, these teeth can often last throughout childhood and adolescence thus ensuring that a young patient does not have the social handicap of a missing tooth and a prosthesis and has the maximum restorative options available to them as they enter adulthood.
\end{abstract}

\title{
Learning Objectives:
}

After reading this article, the reader will:

1. Gain an understanding of the potential sequelae of dental trauma.

2. Understand the importance of effective monitoring post trauma.

3. Appreciate the different scenarios in which endodontic treatment is indicated and the benefit of timely intervention/referral.

4. Receive up to date information regarding the clinical aspects of endodontic treatment of traumatised anterior teeth in paediatric patients.

\section{Introduction:}


Approximately 1 in 4 individuals will sustain a traumatic dental injury to their permanent dentition ${ }^{1}$. It is therefore likely that patients sustaining a traumatic injury will present to general dental practice.

The important roles for the general dental practitioner in the management of these injuries include:

a. Initial assessment and diagnosis of the injury.

b. Immediate injury management.

c. Appropriate monitoring and follow up.

d. Identifying when specialist input is required and making an appropriate referral.

The online website dentaltraumaguide.org ${ }^{2}$ can provide helpful up to date advice on the assessment, diagnosis and management of each injury.

\section{The outcome of dental trauma:}

Depending on the type of injury sustained, the dental pulp and/or periodontal ligament can sustain varying degrees of damage. Unfavourable outcomes following dental trauma can include ${ }^{3}$ :

1. Pulpal necrosis

2. Inflammatory related resorption

3. Replacement resorption (ankylosis). 
These are explored in greater detail below.

\section{Pulpal Necrosis:}

Dental trauma can threaten pulpal health by: ${ }^{3}$

- Bacterial invasion of dentinal tubules exposed due to fracture.

- Direct exposure of the pulp to bacterial contamination from saliva following a complicated crown fracture.

- Exposure of the pulp to the periodontal ligament following a root fracture.

- Partial/total severance or crushing of the pulp as it enters the apical foramen or at the level of a root fracture for luxation injuries. Healing following this type of damage is by pulpal regeneration. This is more likely to occur when teeth have incomplete root development and a wide apical foramen.

Table 1 outlines the risk of pulp necrosis for each type of dental injury. It is worth noting:

- The risk of pulpal necrosis is relatively low for isolated hard tissue injuries. However, the presence of a hard tissue injury will increase the risk of necrosis when seen concurrently with periodontal ligament injuries.

- The risk of pulp necrosis is higher for teeth with complete root development. 
- The risk of pulp necrosis increases with increasing severity of periodontal ligament injury.

\begin{tabular}{|l|l|l|}
\hline Injury & $\begin{array}{l}\text { Incomplete root } \\
\text { development }\end{array}$ & Complete root development \\
\hline Uncomplicated Crown fracture & $0 \%$ & $5.1 \%$ \\
\hline Complicated crown Fracture & $0 \%$ & $6.2 \%$ \\
\hline Root fracture & $0 \%$ & $26.8 \%$ (a) \\
\hline Concussion & $0 \%(a)$ & $3.5 \%(a)$ \\
\hline Subluxation & $0 \%(a)$ & $12.5 \%(a)$ \\
\hline Extrusion & $5.9 \%(a)$ & $56.5 \%(a)$ \\
\hline Lateral Luxation & $4.7 \%(a)$ & $65.1 \%(b)$ \\
\hline Intrusion & $50 \%(a)(b)$ & $100 \%$ \\
\hline Avulsion & $70 \%(b)(c)$ & $100 \%$ \\
\hline
\end{tabular}

Risk of Pulp Necrosis by type of injury at 12 months post injury. Compiled from dentaltraumaguide.org ${ }^{2}$.

(a) increased risk if concurrent crown fracture

(b) Risk increases at 3 and 10 years after injury

(c) Increased risk with prolonged extra alveolar time

Monitoring of the traumatised dentition will include assessment for possible development of pulpal necrosis, and this is outlined below. When pulpal necrosis is diagnosed endodontic management will be required. For injuries, where revasularisation is unlikely, endodontic treatment should be initiated prior to the development of unfavourable outcomes. This includes the following ${ }^{2}$ :

- Avulsion of a tooth with complete root development.

- Intrusion of a tooth with complete root development. 
It is recommended that extirpation and dressing with non-setting calcium hydroxide is normally completed 7-10 days after avulsion injuries and 3-4 weeks after intrusion injuries, meeting the criteria above $\mathrm{e}^{2}$. A delay in commencing this treatment can increase the risk of adverse outcomes ${ }^{4}$.

\section{$\underline{\text { 2. Inflammatory related resorption: }}$}

Inflammatory related resorption (external inflammatory resorption or internal inflammatory resorption) occurs when there is both damage to the periodontal ligament and uncontrolled pulpal infection ${ }^{3,5}$. If this is not identified and managed promptly by endodontic treatment, thus removing the source of infection, it can cause significant damage to the tooth.

Table 2 outlines the risk of inflammatory related resorption for each type of dental injury. It is worth noting that because isolated crown injuries do not result in periodontal ligament damage, they do not result in inflammatory resorption. However, as with pulp necrosis, crown injuries will increase the risk of inflammatory resorption if seen in combination with periodontal ligament injuries.

\begin{tabular}{|l|l|l|}
\hline Injury & $\begin{array}{l}\text { Incomplete root } \\
\text { development }\end{array}$ & Complete root development \\
\hline Uncomplicated Crown fracture & $0 \%$ & $0 \%$ \\
\hline Complicated crown Fracture & $0 \%$ & $0 \%$ \\
\hline Root fracture & $0 \%$ & Nil available data \\
\hline Concussion & $0 \%$ & $0 \%$ \\
\hline Subluxation & $0 \%(a)$ & $0 \%(a)$ \\
\hline Extrusion & $2.9 \%$ & $0 \%$ (a) \\
\hline Lateral Luxation & $0 \%(a)$ & $1 \%$ (b) \\
\hline Intrusion & $33.3 \%$ (a) & $4.8 \%$ (a) \\
\hline
\end{tabular}


Risk of infection related resorption by type of injury at 12 months post injury. Compiled from dentaltraumaguide. org $^{2}$.

(a) increased risk if concurrent crown fracture

(b) Risk increases at 3 and 10 years after injury

(c) Increased risk with prolonged extra alveolar time

\section{$\underline{\text { 3. Replacement resorption (ankylosis) }}$}

This occurs following a significant injury to the periodontal ligament. It represents fusion of the alveolar bone and root surface with the ankylosed root becoming part of the normal bone remodelling system ${ }^{3}$. Over time the tooth will be replaced by bone leading to eventual tooth loss. In a growing child this can result in infraocclusion ${ }^{6}$.

Extraction of a permanent maxillary incisor results in significant reduction of supporting tissue ${ }^{7}$ and therefore it is helpful to retain the ankylosing tooth or root as long as possible to retain bone and assist future tooth replacement. De-coronation and root burial can be considered where there is significant infraocclusion in an attempt to avoid apical migration of the gingival tissues while preserving the vertical height and width of the alveolar ridge ${ }^{6}$.

Ankylosis is not related to pulpal necrosis and will only occur if there is an absence of infection within the root canal space ${ }^{5}$. When ankylosis is identified it would be prudent to refer the patient for inter-disciplinary management to consider the longterm management and ultimate replacement of the tooth ${ }^{5}$. Endodontic treatment is not appropriate and can complicate future management; obturation materials left in a 
resorbing canal can impede complete bone healing and leave a foreign body in what would otherwise be a good bone site for future tooth replacement.

Table 3 outlines the risk of replacement resorption for each type of dental injury.

\begin{tabular}{|l|l|l|}
\hline Injury & $\begin{array}{l}\text { Incomplete root } \\
\text { development }\end{array}$ & Complete root development \\
\hline Uncomplicated Crown fracture & $0 \%$ & $0 \%$ \\
\hline Complicated crown Fracture & $0 \%$ & $0 \%$ \\
\hline Root fracture & $0 \%$ & $1.5 \%$ \\
\hline Concussion & $0 \%$ & $0 \%$ \\
\hline Subluxation & $0 \%$ & $0 \%(\mathrm{a})$ \\
\hline Extrusion & $0 \%$ & $0 \%$ \\
\hline Lateral Luxation & $0 \%$ & $1 \%$ \\
\hline Intrusion & $5.6 \%(\mathrm{a})$ & $10.3 \%(\mathrm{a})(\mathrm{b})$ \\
\hline Avulsion & $36.4 \%(\mathrm{~b})(\mathrm{c})$ & $63.1 \%(\mathrm{~b})(\mathrm{c})$ \\
\hline
\end{tabular}

Risk of ankylosis by type of injury at 12 months post injury. Compiled from dentaltraumaguide. org $^{2}$.

(a) increased risk if concurrent crown fracture

(b) Risk increases at 3 and 10 years after injury

(c) Increased risk with prolonged extra alveolar time

\section{Monitoring the traumatised dentition:}

Traumatised teeth should be monitored clinically and radiographically for possible sequelae, at intervals determined by the type of injury sustained. These intervals are outlined in the IADT 2012 guidelines ${ }^{8,9}$.

For teeth where endodontic treatment is not initiated at 7-10 days post injury, (outlined above), root canal treatment should be initiated when clinical and radiographic examination suggests the pulp is irreversibly damaged and pulpal health unlikely to be regained. If there is uncertainty about the health of the pulp, endodontic treatment should not be undertaken and the tooth should instead be kept under review.

A diagnosis of pulpal necrosis is based on a combination of radiographic findings and clinical signs/symptoms including: 
- Sensibility testing

- Presence of a sinus and/or swelling

- Tenderness to percussion and/or palpation

- Tooth colour

- Tooth mobility

- Lack of continued root growth seen radiographically

- Radiolucency at the tooth apex or adjacent to a root fracture line

- Radiographic evidence of inflammatory resorption

\section{Endodontic management of the traumatised tooth:}

It would be appropriate for endodontic treatment of teeth with closed apices and an absence of resorption to be managed within general practice. The following however should be referred for specialist advice or treatment:

1. Evidence of inflammatory or replacement resorption.

2. Endodontic management of a root fracture.

3. Endodontic management of a tooth with incomplete root development.

\section{Evidence of inflammatory or replacement resorption.}

Patients with inflammatory or replacement resorption should be referred for a specialist opinion. However given the rapid progression of inflammatory resorption the pulp should be extirpated prior to referral and the canal dressed with a root canal 
medicament such as calcium hydroxide, in an attempt to control pulpal infection and slow down the resorption process.

\section{Endodontic management of a root fracture.}

Pulp necrosis following a root fracture is normally limited to the coronal root fragment. Endodontic treatment is therefore completed up to the fracture line only ${ }^{10}$. This poses similar endodontic challenges to the tooth with an immature apex as there is no constriction at the fracture site to condense root filling material.

\section{Endodontic management of a tooth with incomplete root development.}

Completion of root development of $\mathrm{t}$ permanent incisors, normally occurs in childhood, e.g. the maxillary central incisor normally completes its root development before the age of around 10-11 years ${ }^{11}$.

Completion of root development and increase in the dentinal wall thickness is reliant on the presence of a vital pulp and functioning epithelial root sheath of Hertwig. When pulpal necrosis and cessation of root development occur in a tooth with an immature root, the apex will remain wide-open with thin dentinal walls and a funnel shaped root canal.

Endodontic management of a tooth with an immature apex poses a number of challenges:

a) Behaviour management in a young child.

b) Isolation of teeth in the mixed dentition.

c) Difficulty in achieving adequate debridement of the root canal due to its shape. 
d) Possible irrigant and medicament escape through the open apex.

e) Lack of an apical constriction or barrier against which root filling materials can be condensed.

\section{Challenges of Endodontic Treatment of Teeth with immature apices}

\section{a) Behaviour management}

The majority of patients presenting for endodontic treatment of a tooth with an open apex will be of primary school age. This can pose challenges which can in part be aided by behaviour management techniques.

The clinician should ascertain the child's co-operative ability and ask about previous dental treatment they have experienced. It is not uncommon for a paediatric trauma patient to present with a caries free, unrestored dentition. This is encouraging with regards to caries prevention, but means that every stage of endodontic treatment is alien territory for the uninitiated patient.

It is useful to provide a clear explanation of the procedure of endodontic treatment, outlining the separate stages/appointments and supporting this verbal information with a written leaflet is appreciated by parents.

In the author's experience, parents often associate "root canal treatment" with pain and failure ${ }^{12}$. It is often helpful to address these preconceptions at the outset and explain endodontic treatment in reference to managing a traumatised tooth.

Often, paediatric patients attend with dentally anxious parents or carers. Good teamwork between the dentist, dental nurse, parent and patient is crucial in effective behaviour management ${ }^{13}$ : consider a sensitive conversation about who the most helpful chaperone would be going forward.

Discussion of behavioural management techniques ${ }^{13}$ that have proved helpful in the past can be useful, and are a good way to involve the parent and child in their care.

Local anaesthetic is normally administered for the pulp extirpation, not usually necessary for subsequent visits as anterior infiltrations can be uncomfortable and it can exhaust a patient's ability to co-operate early in the appointment.

The WAND STA system is the local anaesthetic delivery system of choice in the authors' department. It is a computerised system which delivers LA at a slow, steady rate; reducing the discomfort of LA delivery ${ }^{14}$. It can be used for conventional buccal and palatal infiltrations or for single tooth anaesthesia (STA). 
For anxious or inexperienced patients, early planning for inhalation sedation during the extirpation can be very useful. This usually proves to be the most challenging appointment, and if it is completed successfully the patient can be weaned off inhalation sedation for subsequent appointments, improving access to the upper anterior region without a nasal mask as an obstruction.

\section{b) Isolation of teeth in the mixed dentition}

There are a number of challenges to consider when isolating a traumatised tooth in a paediatric patient.

These include:

- Time required

- Local anaesthetic for clamp placement

- Partially erupted teeth

- Immature gingival tissues

- Spaced dentition, missing adjacent teeth

A commonly used technique for isolation uses DryDam ${ }^{\circledR}$, wedjets and liquid dam ${ }^{15}$. DryDam ${ }^{\circledR}$, does not require a rubber dam frame, as the patient's ears are used to hold it in place. Use of DryDam ${ }^{\circledR}$, retained with floss ligatures can be a helpful aid where endodontic clamps will not reliably stay in position on partially erupted teeth. There are many useful video guides available on the internet demonstrating how to tie a floss ligature, an example is https://www.youtube.com/watch?v=XgaCUiGgDJA

\section{c) Pulpal anatomy of the immature incisor}

The anatomy of the pulp canal of an immature incisor differs from a fully developed tooth.

The pulp chamber within the crown is large, with prominent pulp horns. Immature teeth have wide apical foramen, thin dentinal walls and are often shorter in length than a fully mature incisor.

The anatomy of the immature incisors requires consideration of the following ${ }^{16}$ :

- Access cavities must be of sufficient size to ensure complete removal of pulpal remnants from the crown, which can result in discolouration if left..

- Larger handfiles are required for immature teeth and rotary files are often less useful for canal preparation.

- With immature apices, care should be taken when interpreting apex locator results and if a working length radiograph is taken, it is often useful to use a larger handfile, \#40-60, to help clarify the position of the apex on the radiograph ${ }^{17}$.

- The coronal access should be sufficient to allow straight line access, and handfiles should be used with care to avoid over instrumentation of the fine dentinal walls. 
- Canal debridement relies on chemical debridement through use of irrigation solution and canal medicaments and mechanical debridement of the already thin dentinal walls should be avoided.

- The shorter root length and immature apex can be of concern when carrying out canal irrigation.

- Lack of an apical constriction or barrier against which root filling materials can be condensed, precludes the use of standard obturation techniques.

\section{d) Possible irrigant and medicament expel due to the open apex}

Sodium hypochlorite is the irrigant of choice ${ }^{18}$. Extrusion of this into the apical tissues must be avoided. Practical advice to avoid this is outlined below:

- Establish a working length, prior to using irrigant. Ensure a bung is placed on the syringe needle at the working length, as a guide.

- Ensure good isolation of the tooth with good suction using an appropriate narrow aspirator tip and use a slow and steady pressure to deliver the irrigant through a Luer lock tip.

- The author commonly describes the irrigant to the patient as "disinfectant" for the tooth and finds it useful to show the patient the syringe in advance, clarifying it is NOT an injection but needs to be very narrow in shape to allow it to clean inside the tooth like a water pistol. Describing the smell as "like the swimming pool" is usually well understood by patients.

e) Lack of an apical constriction or barrier to condense root filling materials

In a traumatised immature incisor, the treatment aim is to achieve apexification to allow satisfactory obturation of the canal.

Traditionally, this was achieved by dressing the canal with non-setting calcium hydroxide and periodical testing for calcific barrier formation. The calcium hydroxide dressing would be replaced initially after 4 weeks, then at 3 monthly intervals with the average time for apical barrier formation being 6 months ${ }^{19}$.

The major disadvantage of this procedure is that extended exposure to calcium hydroxide weakens the dentinal walls and results in decreased fracture resistance of the treated tooth ${ }^{20,21}$.

Calcium hydroxide apexification has largely been superseded by one visit apical barrier placement ${ }^{18}$. This technique involves non- surgical placement of a suitable material (most commonly Mineral Trioxide Aggregate (MTA)) at the apex of an immature root canal, thereby creating a barrier against which a root filling of guttapercha can then be condensed.

This technique involves at least 2 visits. At the initial visit the non-vital canal is extirpated and debrided with gentle filing, copious irrigation and placement of nonsetting calcium hydroxide which is left for up to 30 days. Assuming there is no 
ongoing signs or symptoms of infection, MTA is then placed at the apex of the root canal at the following visit. Given the setting time of MTA, a third visit was previously required for gutta percha placement, however with more recent formulations of MTA, the final setting time is fifteen minutes ${ }^{22}$, allowing plug placement and obturation of the canal during one appointment.

Apexification with MTA has a number of advantages over the previous technique.

- The rapid completion of treatment has positive implications for the patient and their family, reducing time off school, number of appointments and travel.

- Limiting non-setting calcium hydroxide dressing to 30 days following by placement of MTA results in no detrimental effects on fracture resistance ${ }^{23}$.

\section{Conclusion:}

This paper highlights the potential sequelae following dental trauma and outlines when intervention may be indicated. It outlines challenges involved in endodontic management of the non-vital immature incisor, including behaviour management in a young child, isolation of teeth in the mixed dentition, difficulty achieving adequate debridement of the root canal due to its shape, possible irrigant and medicament escape through an open apex and lack of an apical constriction or barrier against which root filling materials can be condensed. This article describes techniques to manage these difficulties. Some of these techniques are more suited to specialist centres, and guidance is provided about the appropriate to refer a patient for specialist treatment.

\section{$\underline{\text { MTA Placement Technique: Table } 4}$}

LA not necessarily required

Standard rubber dam placement

Satisfactory access to canal and canal shaping

Confirmation of clean, dry canal

Confirmation of working length ${ }^{17}$

Select correct diameter of MTA carrier and place bung 4mm short of working length ( $2 \mathrm{~mm}$ to allow for length of MTA pellet, $2 \mathrm{~mm}$ for packing)

Place MTA pellets in canal and pack with appropriate size of MTA packer, with bung $2 \mathrm{~mm}$ short of apex

When MTA plug estimated at least $5 \mathrm{~mm}$ in length, periapical radiograph to confirm placement and appropriate length

If MTA plug satisfactory, proceed with thermoplastic obturation of remainder of canal. 


\section{$\underline{\text { References }}$}

1. Lam R. Epidemiology and outcomes of traumatic dental injuries: a review of the literature. Australian Dental Journal 2016; 61(Supp 1): 4-20.

2. Dentaltraumaguide.org. Dental Trauma Guide. Available from: https://dentaltraumaguide.org [Accessed 8 April 2020].

3. Andreasen JO and Andreasen FM (2007), Avulsions In Textbook and color atlas of traumatic injuries to the teeth, ed.4th Andreasen, J. O., Andreasen, F. M., and Andersson, L. pp. 444-488. Blackwell Munksgaard, Copenhagen.

4. Hinckfuss $\mathrm{SE}^{1}$, Messer LB. An evidence-based assessment of the clinical guidelines for replanted avulsed teeth. Part I: Timing of pulp extirpation. Dental Traumatol 2009; 25 (1): 32-42.

5. Day PF and Gregg TA. UK National Clinical Guidelines in Paediatric Dentistry . Treatment of Avulsed Teeth in Children [internet]. [London]: BSPD; 1998 [updated 2012; cited 2020 Apr 08]. Available from https://www.bspd.co.uk/Portals/0/Public/Files/Guidelines/avulsion_guidelines _v7_final_.pdf

6. Malmgren B. Decoronation: how, why, and when?. J Calif Dent Assoc. 2000; 28(11): 846-54.

7. Rodd HD, Malhotra R, O'Brien CH, Elcock C, Davidson LE, North S. Change in supporting tissue following loss of a permanent maxillary incisor in children. Dent Traumatol 2007; 23(6): 328-32.

8. Diangelis AJ, Andreasen JO, Ebeleseder KA, Kenny DJ, Trope M, Sigurdsson A et al. International Association of Dental Traumatology guidelines for the 
management of traumatic dental injuries: 1 . Fractures and luxations of permanent teeth. Dent Traumatol. 2012; 28(1): 2-12.

9. Andersson L, Andreasen JP, Day P, Heithersay G, Trope M, Diangelis AJ et al. International Association of Dental Traumatology guidelines for the management of traumatic dental injuries: 2. Avulsion of permanent teeth. Dent Traumatol. 2012; 28(2): 88-96.

10. Cvek M, Mejare I, Andreasen JO. Conservative endodontic treatment of teeth fractured in the middle or apical part of the root. Dent Traumatol 2004; 20 (5): 261-269.

11. Nolla C. The Development of the Permanent Teeth. Journal of Dentistry for Children. 1960;27:245-66.

12. Chandraweera L, Goh K, Lai-Tong J, Newby J, Abbott P. A survey of patients' perceptions about, and their experiences of, root canal treatment. Australian Endodontic Journal. 2019;45(2): 225-232

13. Campbell C, Soldani F, Busuttil-Naudi A, Chadwick B. Clinical guidelines in paediatric dentistry: update of non-pharmacological behaviour management guideline. British Society of Paediatric Dentistry, 2011. Accessed on 7/5/2020 at https://www.bspd.co.uk/Portals/0/Public/Files/Guidelines/Nonpharmacological\%20behaviour\%20management\%20.pdf

14. Giannetti L, Forabosco E, Spinas E, Re D, Murri Dello Diago A. Single tooth anaesthesia: a new approach to the paediatric patient. A clinical experimental study. European Journal of Paediatric Dentistry. 2018;19(1);40-43

15. Baughan S, Casaus A, Jiteshkumar Haria P, Coomaraswamy K. Technique tips: moisture control in children. Dent Update. 2019; 46: 291-293 
16. Phillips J, Srinivasan V. Paediatric dentistry: The management of non-vital immature permanent incisors. Dental Update. 2014;41: 596-604.

17. Kin YJ, Chandler NP. Determination of working length for teeth with wide or immature apices: a review. Int Endod J. 2013 Jun;46(6):483-91.

18. Vaidyanathan M, Mitchell JC, Patel S and Pitt Ford H. Clinical guidelines in paediatric dentistry: management and root canal treatment of non-vital immature permanent incisor teeth. British Society of Paediatric Dentistry, 2010. Accessed on $7 / 5 / 2020$ at https://www.bspd.co.uk/Portals/0/Public/Files/Guidelines/Management\%20an d\%20Root\%20Canal\%20Treatment $\% 20$ of $\% 20$ Non\%20Vital\%20Immature $\% 2$ OPermanent\%20Incisor\%20Teeth.pdf

19. Finucane D, Kinirons MJ. Non-vital immature permanent incisors: factors that may influence treatment outcome. Dental Traumatology.1999;15: 273-277

20. Andreasen JO, Farik B, Munksgaard EC. Long-term calcium hydroxide as a root canal dressing may increase risk of root fracture. Dent Traumatol. 2002 Jun;18(3):134-7.

21. Batur YB, Erdemir U, Sancakli HS. The long-term effect of calcium hydroxide application on dentin fracture strength of endodontically treated teeth. Dent Traumatol. 2013 Dec;29(6):461-4.

22. Malhotra N, Agarwal A, Mala K. Mineral trioxide aggregate: part 2 - a review of the material aspects. Compendium of Continuing Education in Dentistry. 2013; 34:3.

23. Andreasen JO, Munksgaard EC, Bakland LK. Comparison of fracture resistance in root canals of immature sheep teeth after filling with calcium hydroxide or MTA. Dental Traumatol. 2006 Jun;22(3):154-6. 
